\title{
FATORES DETERMINANTES PARA O AVANÇO DA ENERGIA EÓLICA NO ESTADO DO CEARÁ FRENTE AOS DESAFIOS DAS MUDANÇAS CLIMÁTICAS
}

\author{
Mônica Cavalcanti Sá de Abreu \\ mabreu@ufc.br \\ Universidade Federal do Ceará - Fortaleza, CE / Brasil \\ Alexandra Alencar Siebra \\ alesiebra@hotmail.com \\ Universidade Federal do Ceará - Fortaleza, CE / Brasil \\ Larissa Teixeira da Cunha \\ larissatc@gmail.com \\ Universidade Federal do Ceará - Fortaleza, CE / Brasil \\ Sandra Maria dos Santos \\ smsantos@ufc.br \\ Universidade Federal do Ceará - Fortaleza, CE / Brasil
}

http://dx.doi.org/10.1590/1413-2311060201238406

Recebido em 09/10/2013

Aprovado em 20/02/2014

Disponibilizado em 01/08/2014

Avaliado pelo sistema double blind review

Revista Eletrônica de Administração

Editor: Luís Felipe Nascimento

ISSN 1413-2311 (versão on-line)

Editada pela Escola de Administração da Universidade Federal do Rio Grande do Sul.

Periodicidade: Quadrimestral

Sistema requerido: Adobe Acrobat Reader.

\section{RESUMO}

$\mathrm{O}$ trabalho identifica fatores determinantes para o avanço da geração da energia eólica frente aos desafios das mudanças climáticas. A pesquisa empregou métodos qualitativos para a obtenção de dados e configura-se como descritiva e exploratória. Foram realizadas entrevistas semiestruturadas com participantes do setor eólico, tomando o estado do Ceará como unidade de estudo. Os resultados indicam que as percepções e pressões dos stakeholders, as políticas públicas e os investimentos tecnológicos são determinantes para que a participação da energia eólica na matriz energética Brasileira seja ampliada. A perspectiva de um preço mais competitivo do KWh produzido é vital para o crescimento dos investimentos na implantação de parques eólicos. As empresas estão investindo na eficiência operacional dos aerogeradores e na adequação tecnológicas as características dos ventos do Nordeste Brasileiro. O diálogo com a comunidade revela-se também determinante para a viabilidade de implantação dos parques eólicos. A pesquisa aponta um cenário de incertezas para a segurança energética do país, no qual as empresas planejam suas estratégias com base nos benefícios oriundos de uma intensa participação do governo para alavancar este setor.

Palavras-chave: energia eólica; estratégias empresariais; mudanças climáticas; stakeholders; tecnologia; políticas públicas.

REAd | Porto Alegre - Edição 78 - N 2 - maio/agosto 2014 - p. 274-304 
Mônica Cavalcanti Sá de Abreu, Alexandra Alencar Siebra, Larissa Teixeira da Cunha $\&$ Sandra Maria dos Santos

\title{
DETERMINANT FACTORS FOR THE WIND SECTOR ADVANCES IN THE STATE OF CEARA IN RESPONSE TO CLIMATE CHANGE
}

\begin{abstract}
The study analyzes determinants factors and corporate responses to the challenges of climate change to develop wind farms. We conducted a field study with semi-structured interviews with the participants of the installed wind power in the state of Ceará. The results indicate that stakeholder pressure, the public policies and technology investments are crucial for the sector to achieve competitive prices in the energy market. Companies have invested in improving the operational efficiency of the turbines and the appropriateness of the technology features of the winds of the State of Ceará. The dialogue with the community is decisive for the deployment of wind farms. The research points to a scenario of uncertainty for the energy security of the country, where the companies plan their strategies based on the benefits derived from a close involvement of the government to boost this sector.
\end{abstract}

Keywords: wind power; corporate strategies; climate change; stakeholders; technology and public policy.

\section{DETERMINANTES PARA EL ADELANTO DE LA ENERGÍA EÓLICA EN EL ESTADO DE CEARÁ ADELANTE A LOS DESAFÍOS DEL CAMBIO CLIMÁTICO}

\section{RESUMEN}

El documento identifica los factores de promoción de la generación de energía eólica para afrontar los retos del cambio climático. La investigación utilizó métodos cualitativos para la recolección de datos y se configura como un término descriptivo y exploratorio. Entrevistas semi-estructuradas se realizaron con participantes de la industria eólica, teniendo el estado de Ceará como unidad de estudio. Los resultados indican que las políticas públicas y las inversiones en tecnología son cruciales para el sector para avanzar en el mercado energético. La perspectiva de un precio más competitivo que KW producidos a partir de la energía eólica es vital para la definición de las estrategias de negocio. El diálogo con la comunidad también se pone de manifiesto la determinación de la viabilidad de la implantación de parques eólicos. Las empresas han invertido en la mejora de la eficiencia operativa de las turbinas y la adecuación de la tecnología a las características de los vientos del Estado de Ceará. La investigación apunta a un escenario de incertidumbre para la seguridad energética del país en el que las empresas planifican sus estrategias con base en los beneficios derivados de la participación del gobierno intensa para aprovechar esta industria.

Palabras clave: viento; las estrategias de negocios; cambio climático; actores; la tecnología y las políticas públicas. 
Fatores determinantes para o avanço da energia eólica no Estado do Ceará frente aos desafios das mudanças climáticas

\section{INTRODUÇÃO}

Kolk e Pinkse (2007) afirmam que as empresas têm desenvolvido estratégias diferenciadas para lidar com os efeitos das mudanças climáticas. As empresas necessitam cumprir regulamentos e sofrem pressão dos stakeholders para a adoção de medidas coerentes com o papel que delas se espera, que hoje transcende a maximização dos lucros, a geração de bens e a prestação de serviços.

Lewis e Viser (2007) destacam que as preocupações com as mudanças climáticas e a adoção de práticas de responsabilidade social corporativa favorecem o crescimento da indústria de energia renovável no mundo. Aliado a esses fatores, evidencia-se a preocupação pela segurança energética, que está sendo impulsionada por mecanismos governamentais. Valentine (2010) afirma que uma política de diversificação da matriz energética deve ter instrumentos capazes de diminuir o custo da geração de energia por fontes alternativas.

As principais práticas adotadas envolvem as tarifas feed-in (FITs), os subsídios de capital ou subvenções, os créditos fiscais ao investimento, a negociação de certificados verdes, os pagamentos diretos à produção de energia e o investimento público direto ou por meio de programas de financiamento da geração de energia renovável (ALISHAHI; MOGHADDAM; SHEIKH-EL-ESLAMI, 2011; SAIDUR et al., 2010).

Como consequência dos investimentos, observa-se a criação de oportunidades de trabalho, o aumento da segurança energética, a proteção para os consumidores contra os picos de preços ou a escassez de oferta de combustíveis fósseis e a redução da emissão dos gases do efeito estufa (GEE) (SAIDUR et al., 2010). Paralelamente, a geração de energia eólica não requer grandes ou exclusivas áreas, que podem ser destinadas, concomitantemente, para a agricultura e a pecuária.

Os recursos eólicos mundiais concentram-se nas regiões costeiras de todos os continentes e o seu potencial estimado corresponde a cerca de quatro vezes o consumo mundial atual de energia elétrica (CNI, 2009). Os países como o Brasil, Argentina, Rússia, Finlândia e Turquia, passaram a investir no setor de energia eólica buscando superar as barreiras tecnológicas para se consolidar como uma alternativa bem sucedida geração da energia (GAN e SMITH, 2011, ALISHAHI, MOGHADDAM e SHEIKH-EL-ESLAMI, 2011, SAIDUR et al., 2010 e BERMANN, 2008; CNI, 2009).

De acordo com o Renewable 2010 Global Status Report da REN21 (2010), em 2009, a capacidade instalada de energia eólica no Brasil correspondia a quase um quarto do total da capacidade instalada no mundo. Segundo a ANEEL (2012), o Brasil possui, no total,

REAd | Porto Alegre - Edição 78 - N² 2 - maio/agosto 2014 - p. 274-304 
Mônica Cavalcanti Sá de Abreu, Alexandra Alencar Siebra, Larissa Teixeira da Cunha \& Sandra Maria dos Santos

2.597 empreendimentos em operação, que geram 119.442.605 KW de potência outorgada. Está previsto, para os próximos anos, uma adição de 51.103.649 KW na capacidade de geração do País, proveniente dos 176 empreendimentos (em construção) e de mais 533 outorgados.

A região Nordeste concentra mais de $35 \%$ da potência eólica brasileira (GWEC, 2011). O Estado do Ceará, em particular, possui um grande potencial de geração off-shore, pois possui uma plataforma continental rasa, com média de $8 \mathrm{~m}$ de profundidade em cerca de $35 \%$ de sua faixa litorânea. Estas características reduzem os custos na instalação de uma usina, bem como facilitam a manutenção e durabilidade de aerogeradores (ADECE, 2010).

Contudo, existem barreiras que inibem o progresso da utilização desta fonte de energia. Valentine (2010) afirma que apenas os instrumentos de políticas públicas não são suficientes para incentivar o uso da energia eólica. Fischlein et al. (2010) reforçam que os fatores sociopolíticos podem reduzir a distância que existe entre a concepção de políticas energéticas de baixa emissão de carbono e a respectiva implantação de tecnologias de energias renováveis para mitigação dos efeitos das mudanças climáticas.

Questões como a transmissão da energia gerada por fonte eólica e o acesso ao mercado surgem como os maiores desafios enfrentados para melhorar a competitividade. Barradale (2010) afirma que a ausência de crédito provoca a desaceleração dos investimentos. A incerteza sobre as políticas energéticas associadas aos acordos de compra de energia ampliam significativamente os riscos dos investimentos.

Existem também preocupações ambientais e sociais, que devem ser consideradas ao se investir na geração de energia eólica. Terciote (2002) ressalta que impactos ambientais, envolvem a colisão de pássaros migratórios nas estruturas e turbinas eólicas, o impacto visual dos parques eólicos e o ruído gerado pelo movimento das pás. Este ruído de origem aerodinâmica pode ser considerado perturbador, notadamente no período noturno, e pode gerar reações adversas da comunidade vizinha.

Baseado no exposto, esta pesquisa identifica fatores que influenciam o avanço da energia eólica frente aos desafios da mudança climática. O trabalho a apresenta as expectativas dos stakeholders, em relação as empresas de geração de energia eólica, o papel do governo, através das políticas públicas, e das tecnologias para o avanço do setor de forma sustentável, que atenda à demanda crescente de energia sem ampliar os riscos da mudança climática. 
Fatores determinantes para o avanço da energia eólica no Estado do Ceará frente aos desafios das mudanças climáticas

Para atingir o objetivo proposto, a próxima seção aborda a gestão estratégica, as políticas públicas e o papel da tecnologia em um mercado de baixa emissão de carbono. Em seguida, a metodologia da pesquisa qualitativa é apresentada, e depois são introduzidos os resultados e discussões oriundos das entrevistas com atores chaves do setor eólico. Por fim, o estudo contribui com a apresentação de um panorama das principais influências para o crescimento energia eólica no Brasil, tomando o Estado do Ceará como unidade de estudo.

\section{REFERENCIAL TEÓRICO}

\subsection{Gestão Estratégica em um Mercado de Baixa Emissão de Carbono}

As empresas necessitam desenvolver uma ampla e inclusiva estratégia que seja capaz de garantir vantagens competitivas em um mundo de carbono restrito. Shalizi e Lecocq (2010) destacam que a questão fundamental reside em identificar como a mudança climática irá modificar a alocação de recursos nas estratégias empresariais. Para Schultz e Williamson (2005), a gestão estratégica - mercadológica, política e tecnológica - voltada para as mudanças climáticas, envolve a redução de custos e de riscos.

Dessa forma, o engajamento das empresas aumenta à medida que a transição para um mercado de baixa emissão de carbono e as oportunidades são percebidas. Trata-se, portanto, de um debate estratégico, no qual as empresas se engajam como forma de proteger seus investimentos e buscar novas oportunidades de negócios (HOFFMAN, 2007). Hoffman e Woody (2008) afirmam que a avaliação sistemática dos riscos relacionados aos aspectos econômicos, regulatórios, físicos e de reputação, deve ser considerada nos níveis específicos do setor, da indústria e da empresa.

As políticas públicas (domésticas e internacionais) desempenham um papel relevante na transformação dos sistemas econômicos, em especial os energéticos, objetivando o alcance de metas de estabilização dos gases de efeito estufa (NEWELL, 2010). Adicionalmente, Thorne (2008) afirma que as mudanças nas tecnologias e nos comportamentos sociais se mostram necessárias à mitigação dos impactos das mudanças climáticas. Vollebergh e Kemfert (2005) argumentam, no entanto, que existe certo otimismo quanto à capacidade da tecnologia em prover soluções para as questões ambientais.

As reações das empresas às questões climáticas podem ser entendidas ao se considerar as decisões para mitigar os impactos e o grau de interação com outras empresas. Kolk e Pinkse (2005) combinaram estes dois aspectos, a forma de organização (grau de 
Mônica Cavalcanti Sá de Abreu, Alexandra Alencar Siebra, Larissa Teixeira da Cunha \& Sandra Maria dos Santos

interação) e o objetivo principal (intento estratégico), e definiram opções estratégicas para a redução de gases do efeito estufa (GEE).

Quanto à forma de organização, as empresas se diferenciam em três níveis de integração para controlar e mitigar os impactos climáticos. Podem optar por integrar apenas no âmbito interno da empresa, com sua cadeia de suprimentos ou em colaboração com outras organizações (fora da sua cadeia de suprimentos), os quais podem ser concorrentes ou de outros setores. Quanto ao objetivo, as empresas podem focar apenas em inovação, em relação às suas próprias atividades de negócio, ou em compensação das emissões de GEE.

A inovação envolve o desenvolvimento de novas tecnologias ou serviços ambientais com o intuito de reduzir emissões de GEE, por meio de aprimoramento de processos, desenvolvimento de produtos, e/ou combinações de produtos e mercados. A inovação aprimora fundamentalmente os recursos tecnológicos e as competências da empresa. Ao adotarem uma resposta estratégica de inovação, a empresa pode, por exemplo, monitorar as emissões de GEE em seu processo produtivo ou influenciar sua cadeia de suprimentos.

Kolk e Pinkse (2005) afirmam que as empresas que optam por uma estratégia de inovação para mitigação dos efeitos das mudanças climáticas podem vir a estimular o desenvolvimento de processos mais limpos e sustentáveis, além de diminuir os custos relacionados aos seus processos, e, por consequência, obter vantagem competitiva.

Por outro lado, em uma estratégia de compensação, os recursos tecnológicos e as competências da empresa permanecem praticamente inalterados, uma vez que são utilizadas tecnologias desenvolvidas por outras empresas/instituições. Ao optarem por respostas estratégicas de compensação, as empresas podem tomar decisões como transferir suas operações para regiões com menor rigor ambiental. Podem também optar por realizar modificações em seus processos produtivos, como diminuir suas emissões a partir de substituições, ou mesmo continuar suas emissões de GEE e adquirir CERs (Certified Emission Reduction).

Kolk e Pinkse $(2004,2005)$ argumentam também que, dependendo do mercado em que atuam, as empresas respondem de forma diferenciada aos efeitos das mudanças climáticas. Fatores como a localização geográfica, as políticas governamentais, o tamanho da empresa e a cultura organizacional influenciam a tomada de decisão. De acordo com Hoffman e Woody (2008), a questão climática deve ser pensada a partir de uma mudança institucional, envolvendo empresas, governo e sociedade.

REAd | Porto Alegre - Edição 78 - N 2 - maio/agosto 2014 - p. 274-304 
Fatores determinantes para o avanço da energia eólica no Estado do Ceará frente aos desafios das mudanças climáticas

As estratégias empresariais devem estar integradas às necessidades de seus públicos de interesse, não podendo ser determinadas apenas pelos objetivos de seus acionistas. Fassin (2009) reforça a necessidade de identificar as partes interessadas e avaliar sua posição nos grupos de pressão. $\mathrm{O}$ autor apresenta três grupos de partes interessadas. $\mathrm{O}$ primeiro grupo é formado pelos stakeholders com interesses e participação nos objetivos e ações das empresas.

O segundo grupo foi denominado de stakewatchers. Este grupo não tem interesse direto, mas busca proteger os interesses dos stakeholders ou simplesmente acompanhar as ações desempenhadas pelas empresas para alcançar seus objetivos. São reconhecidos como grupos de pressão, pois podem, a partir de sua atenção e interesse, influenciar indiretamente os objetivos das empresas. O terceiro grupo é formado pelos stakekeepers, que não possuem qualquer participação na empresa, porém, exercem sua influência e controle como regulador independente, impondo regras e limites à atuação das empresas.

As três categorias possuem perfis diferenciados. Para os stakeholders a reivindicação é legítima e o poder de influência e a responsabilidade são recíprocos, sendo a empresa responsável por seus interesses. Os stakewatcher possuem poder de influência, mas a empresa não detém o controle dos interesses destas partes. A legitimidade de reinvindicação dos stakekeepers é imposta pelo poder coercitivo.

Ao invés de adotar uma estratégia isolada, sugere-se que seja elaborado um portfólio de ações integradas de inovação, compensação e engajamento com as partes interessadas. Segundo Hoffman (2007), a empresa deve avaliar seu posicionamento no mercado em relação às complexas questões das mudanças climáticas. Estas questões envolvem: reduções de gases de efeito estufa, medidas de aprimoramento operacional, influência sobre regulações, acesso a novas fontes de capital, melhoria do gerenciamento de riscos, consolidação da reputação da empresa e identificação de novas oportunidades de mercado e pressões dos stakeholders. Estas medidas colaboram para uma avaliação da vulnerabilidade da empresa frente aos desafios de um mercado de baixa emissão de carbono.

\subsection{Políticas Públicas de Mitigação e Adaptação às Mudanças do Clima}

As mudanças climáticas representam um desafio para os atores responsáveis pela elaboração de políticas públicas. Trata-se de uma intervenção totalmente diferente daquelas praticadas para corrigir as falhas de mercado (HELM, 2003). A continuação da trajetória 
Mônica Cavalcanti Sá de Abreu, Alexandra Alencar Siebra, Larissa Teixeira da Cunha $\&$ Sandra Maria dos Santos

corrente das políticas de mudanças climáticas, provavelmente, seja ineficiente e custosa (HELM, 2010).

A incapacidade de alcançar os resultados desejados e a imposição de vultosos custos pode causar um colapso no mercado. A explicação para estes resultados insatisfatórios e os altos custos refere-se mais ao desenho das políticas do que ao seu intento. As políticas devem ser concebidas com base em objetivos específicos, como maximizar as possibilidades de sequestro de $\mathrm{CO}_{2}$, e em princípios, como a transparência.

No caso da segurança energética, uma política bem desenvolvida, pode desempenhar um papel vital na mitigação dos impactos do aquecimento global e das possíveis crises de disponibilidade de energia (SAIDUR et al., 2010). De acordo com Fischlein et al. (2010), para que isso ocorra, é necessário compreender os fatores sociopolíticos capazes de reduzir a distância entre a concepção de políticas energéticas de baixa emissão de carbono e a respectiva implantação de tecnologias de energias renováveis.

Dentre estes fatores, Saidur et al. (2010) enumera a legislação, os tratados internacionais, as diretrizes para a conservação de energia, as estratégias tributárias para estimular o setor energético, e os incentivos aos investimentos em novas fontes (geralmente renováveis) de energia. Governos ao redor do mundo estabeleceram metas diversas para o futuro das energias renováveis, todas mediadas por políticas que incluem créditos e isenções fiscais, investimentos em tecnologia e programas de financiamentos.

No caso do Brasil, foi criado o Programa de Incentivo às Fontes Alternativas de Energia Elétrica (PROINFA), instituído pela Lei no 10.438 de 26 de abril de 2002 e revisado pela Lei $\mathrm{n}^{\circ} 10.762$ de 11 de novembro de 2003. O PROINFA tem como objetivo assegurar, por meio das Centrais Elétricas Brasileiras S.A. (ELETROBRAS), empresa de economia mista e de capital aberto, a compra da energia a ser produzida no prazo de 20 (vinte) anos.

O PROINFA tem o objetivo de reduzir a emissão de GEE da ordem de 2,8 milhões de toneladas de $\mathrm{CO}_{2}$ /ano ao incluir as fontes limpas na produção de energia elétrica do país. Com o suporte do Banco Nacional de Desenvolvimento Social (BNDES), o PROINFA financia projetos de geração de energia eólica, pequenas centrais hidrelétricas (PCHs) e uso da biomassa. A Eletrobrás assegura ao empreendedor proteção integral quanto aos riscos de exposição no mercado de curto prazo (BERMANN, 2008).

Por meio de leilões ocorre a venda da energia produzida, no qual a Agência Nacional de Energia Elétrica - ANEEL define o preço mínimo que deve ser pago por KWh produzido. A comercialização de energia elétrica é realizada em dois ambientes de mercado: o

REAd | Porto Alegre - Edição 78 - Nº 2 - maio/agosto 2014 - p. 274-304 
Fatores determinantes para o avanço da energia eólica no Estado do Ceará frente aos desafios das mudanças climáticas

Ambiente de Contratação Regulada - ACR e o Ambiente de Contratação Livre - ACL. Segundo Nogueira (2011), o Brasil apresentou um desempenho surpreendente em 2009 e 2010 nos leilões de reserva e de fontes alternativas com a contratação de mais de 3,8 GW em empreendimentos eólicos.

Paralelamente, o país tem sido um ator chave nas negociações mundiais sobre mudanças climáticas. Segundo Johnson (2001), a larga participação brasileira decorre da necessidade de promover o desenvolvimento social e econômico, e garantia da segurança energética do país. No Brasil, a responsabilidade pela elaboração de políticas públicas relativas ao setor energético compete ao Congresso Nacional, à Presidência da República e ao Ministério das Minas e Energia.

O Comitê Interministerial sobre Mudança do Clima em colaboração com o Fórum Brasileiro de Mudanças Climáticas, a Comissão Interministerial de Mudança Global do Clima, a III Conferência Nacional do Meio Ambiente, bem como com os Fóruns Estaduais de Mudanças Climáticas e organizações da sociedade civil, produziram o Plano Nacional sobre Mudança do Clima. Este plano prevê o aumento da participação das fontes renováveis e energias limpas na matriz energética nacional, o que também figura, como medida de longo prazo, no Plano Nacional de Energia.

Além do Plano Nacional sobre Mudança do Clima, foi instituída a Política Nacional das Mudanças Climáticas (PNMC), com o advento da Lei Federal $n^{\circ} 12.187$, de dezembro de 2009, segundo a qual o Brasil se compromete a promover ações mitigadoras das emissões de GEE, numa escala de 36,10\% a 38,90\% até 2020. Reforça esse comprometimento o surgimento do Decreto $\mathrm{n}^{\mathrm{o}} 7.343$ de 2010, que regulamenta a Lei $\mathrm{n}^{\mathrm{o}} 12.114$ de 2009, responsável pela criação do Fundo Nacional sobre Mudança do Clima (FNMC), que, em suas regras, cria algumas oportunidades para o setor energético, como o incentivo para o desenvolvimento e difusão de tecnologia para mitigação de emissões de GEE.

Observa-se, no entanto, a incipiente participação das empresas na elaboração destas políticas públicas. Hoffman e Woody (2008) sugerem o envolvimento corporativo em assuntos políticos, configurando as estratégias como algo além do que uma mera questão de autointeresse. Para os autores, políticas eficientes podem ser elaboradas a partir de valiosos insights empresariais, visto que o governo sozinho não tem a capacidade de entender as implicações das diferentes opções políticas sobre todos os setores econômicos.

Conforme Kolk e Hoffmann (2007), as complexidades e incertezas relacionadas às políticas climáticas impedem uma resposta mais proativa por parte das empresas. Os

REAd | Porto Alegre - Edição 78 - N² 2 - maio/agosto 2014 - p. 274-304 
Mônica Cavalcanti Sá de Abreu, Alexandra Alencar Siebra, Larissa Teixeira da Cunha \& Sandra Maria dos Santos

autores defendem a unificação e simplificação de políticas públicas com o intuito de ampliar sua eficiência. Por outro lado, as empresas devem adaptar-se as transformações decorrentes das mudanças do clima e que impactam em seu ambiente mercadológico.

\subsection{O Papel Significativo da Tecnologia no Desafio das Mudanças Climáticas}

Em um panorama de carbono restrito, ganha destaque a área de inovação com crescentes investimentos em pesquisa e desenvolvimento. A tecnologia configura-se como um importante elo entre a ampliação da oferta de energia e a redução do impacto ambiental. O termo tecnologia energética refere-se, assim, aos meios de localizar, avaliar, colher, transportar, processar e transformar as formas de energia primária encontradas na natureza para produzir serviços energéticos (GALLAGHER; HOLDREN; SAGAR, 2006).

O desenvolvimento e a implantação de tecnologias energéticas têm sido essencial para o alcance de formas mais limpas e eficientes de produção e consumo de energia. Novas tecnologias permitem mudanças na trajetória do setor de energia, permitindo-lhe oferecer serviços de melhor qualidade, tornar-se mais eficiente e responder a questões ambientais, como a poluição do ar e as mudanças climáticas globais (SAGAR; VAN DER ZWAAN, 2006).

Segundo Thorne (2008), o senso comum encara tecnologia como a manifestação de conhecimento acumulado, estando presente em instituições que as criaram e que continuam a promover o seu desenvolvimento. Vollenbroek (2002) destaca que há uma crescente conscientização de que a inovação deve não somente resultar em fortalecimento econômico, mas também em uma melhor qualidade do meio ambiente.

A substituição das atuais tecnologias exige coerência entre as políticas econômicas, científicas, tecnológicas e industriais, colaborando, assim, para a formação de um sistema de inovação direcionado ao desenvolvimento sustentável e à criação de oportunidades para produtores e consumidores. Bessant e Tidd (2009) corroboram ao afirmarem que para inovar em geração e distribuição de energia é preciso que ocorra a interação de tecnologias emergentes, pressões políticas, sociais e econômicas com a tomada de decisão e comprometimento de recursos por parte das empresas.

A importância da articulação foi constatada por Forsyth (2007), cujo estudo verificou que uma maior colaboração entre investidores, atores estatais e cidadãos (às vezes representados por ONGs) podem reduzir os custos de transferência de tecnologia climática.

REAd | Porto Alegre - Edição 78 - N 2 - maio/agosto 2014 - p. 274-304 
Fatores determinantes para o avanço da energia eólica no Estado do Ceará frente aos desafios das mudanças climáticas

Dessa forma, os benefícios sociais acompanham as atividades redutoras ou sequestradoras de emissões de gases de efeito estufa.

Mathiesen, Lund e Karlsson (2011) destacam que a adoção de políticas para aumentar a quota das energias renováveis faz parte do plano global de resposta às mudanças climáticas. Portanto, investir em tecnologias de conversão mais eficientes pode ter efeitos socioeconômicos positivos, como a criação de oportunidades de emprego e a diminuição das externalidades.

Para Garrone e Grilli (2010), não há dúvidas de que a mudança tecnológica é essencial para lidar com o desafio da mitigação climática. Todavia, subsídios em pesquisa e desenvolvimento (P\&D) por si só não são suficientes, sendo necessária uma combinação de precificação das emissões e de apoio público à $\mathrm{P} \& \mathrm{D}$ para se alcançar uma melhoria significativa do bem-estar.

\section{METODOLOGIA}

A pesquisa empregou métodos qualitativos para a obtenção de dados e se configura como uma pesquisa exploratória e descritiva. A obtenção dos dados ocorreu por meio de entrevistas semiestruturadas com atores chaves do setor eólico. Para cada participante foi elaborado um roteiro específico para a condução das entrevistas. Os sujeitos da pesquisa foram escolhidos de forma não aleatória, considerando-se os seguintes critérios: relevância e acessibilidade. Foram analisadas as relações das empresas geradoras de energia eólica com governo, acionista, investidor, banco, fornecedor de tecnologia, competidores, comunidade e ONGs, conforme apresentados no Quadro 1.

Quadro 1 - Participantes do setor eólico entrevistados na pesquisa.

\begin{tabular}{|l|l|l|}
\hline $\begin{array}{l}\text { Participantes do Setor de Energia } \\
\text { Eólica }\end{array}$ & Código & Cargo \\
\hline $\begin{array}{l}\text { Empresa Geradora de Energia } \\
\text { Eólica }\end{array}$ & E1 & Gerente ambiental \\
\hline Fornecedor de tecnologia & E2 & Proprietário de construtora de parques eólicos \\
\hline Investidor & E3 & Acionista de usinas produtoras de energia eólica \\
\hline Competidoras & E4a & $\begin{array}{l}\text { Gerente de saúde, segurança do trabalho e } \\
\text { sustentabilidade /Brasil }\end{array}$ \\
\cline { 2 - 3 } & E4b & Analista de projetos eólicos e hidráulicos \\
\hline Banco & E5 & Analista de crédito \\
\hline Governo & E6 & $\begin{array}{l}\text { Superintendente da secretaria estadual de meio } \\
\text { ambiente }\end{array}$ \\
\hline ONG & E7 & Relações públicas \\
\hline Comunidade & $\begin{array}{l}\text { E8 } \\
(\mathrm{a}, \mathrm{b}, \mathrm{c}, \mathrm{d}, \mathrm{e}, \mathrm{f}, \mathrm{g}, \mathrm{h}, \mathrm{i}, \mathrm{j})\end{array}$ & $\begin{array}{l}\text { Moradores nas proximidades de um parque eólico } \\
\text { no município de Beberibe. }\end{array}$ \\
\hline
\end{tabular}

Fonte: elaborado pelos autores

REAd | Porto Alegre - Edição 78 - N² 2 - maio/agosto 2014 - p. 274-304 
Mônica Cavalcanti Sá de Abreu, Alexandra Alencar Siebra, Larissa Teixeira da Cunha $\&$ Sandra Maria dos Santos

As entrevistas foram realizadas em 2011 e gravadas com autorização dos entrevistados. Na empresa geradora de energia eólica (E1) foi entrevistada, por duas horas, a gerente ambiental responsável pela administração de quatro usinas em operação do Brasil. A empresa possui parques instalados no estado do Ceará, e que representam 12,3\% do potencial outorgado de energia de fonte eólica (ANEEL, 2012).

O roteiro desta entrevista investigou o cenário atual dos investimentos em energia eólica. Buscou-se compreender quais os fatores que determinam o crescimento do mercado de geração de energia eólica. O roteiro contemplou, ainda, perguntas sobre a influência dos seus stakeholders e além de identificar quais os desafios tecnológicos e o papel das políticas públicas na ampliação da participação da energia eólica na matriz energética nacional.

A entrevista com o fornecedor de tecnologia (E2) teve duração de uma hora. A empresa pesquisada é uma construtora de parques eólicos nos estados do Ceará, Paraíba e Rio Grande do Norte. A empresa possui com sistemas de gestão da qualidade, meio ambiente e saúde e segurança certificados pela ISO 9001, ISO 14001 E OHSAS 18001. Desenvolve projetos sociais que visam contribuir para o desenvolvimento sustentável nas comunidades onde atua, adotando uma política de dar preferência à contratação de profissionais das regiões circunvizinhas às obras que executa e ainda, levar educação ao canteiro de obra.

Para esta entrevista, foram elaboradas perguntas com o intuito de analisar a estrutura de mercado do setor eólico. Foram questionadas as pressões dos stakeholders e o papel tecnologia e as principais inovações adotadas para melhorar a eficiência operacional dos parques eólicos e os desafios do setor.

O entrevistado E3 é um investidor e acionista de uma usina produtora de energia eólica ainda não construída, mas com outorga liberada pela ANEEL. Apesar de ser empresário da construção civil, proprietário de uma empresa com sede em Fortaleza, Ceará, optou por diversificar seu portfólio de negócios investindo em uma Sociedade de Propósito Específica (SPE) para explorar a geração de energia eólica.

Esta entrevista durou 50 minutos e analisou os riscos e oportunidades da mudança climática nos investimentos empresariais, o interesse do crescimento dos investimentos na geração de energia eólica no Brasil, o impacto das políticas públicas, as motivações que impulsionam os investimentos, as oportunidades geradas ao integrar a preocupação ambiental e a expectativa para o cenário das energias renováveis.

REAd | Porto Alegre - Edição 78 - N 2 - maio/agosto 2014 - p. 274-304 
Fatores determinantes para o avanço da energia eólica no Estado do Ceará frente aos desafios das mudanças climáticas

As entrevistas conduzidas com as empresas E4a e E4b foram breves, em torno de 20 minutos cada uma, e serviram apenas para identificar os fatores chaves para a decisão de implantação de parques eólicos no Estado do Ceará e no Nordeste, e o papel das partes interessadas, notadamente, o governo e a comunidade.

$\mathrm{O}$ analista de crédito de um banco público (E5), com experiência em projetos de financiamento para o setor eólico, foi entrevistado por duas horas. A entrevista investigou a contribuição dos bancos de fomento, como BNB e BNDES, na alavancagem do setor de energia eólica, além da identificação dos riscos e dos instrumentos utilizados pelo banco para acompanhar os empreendimentos. Por fim, foram feitas perguntas sobre a projeção de avanço do setor eólico no Brasil e, em especial, no Estado do Ceará.

O Governo do Estado do Ceará (E6), representado pelo superintendente da Secretaria Estadual de Meio Ambiente (SEMACE), foi entrevistado por uma hora. As perguntas identificaram as ações do governo estadual para mitigação e adaptação dos impactos das mudanças climáticas e as políticas públicas de incentivo à geração de energia a partir de fontes renováveis, em especial, a eólica. O roteiro de entrevista identificou também o processo de licenciamento ambiental dos parques eólicos e os instrumentos utilizados para a fiscalização ambiental.

No tocante as ONGs, houve dificuldade de identificar organizações que atuassem com energia eólica. Realizou-se uma pesquisa com uma ONG (E7) que atuou no município de Beberibe, onde está implantado um parque eólico da empresa E1, com duração de 30 minutos. Nesta entrevista foram questionados os fatores determinantes para o sucesso da geração de energia por fontes renováveis, e quais as preocupações que as inquietam, no tocante ao setor de energia eólica, no estado do Ceará.

A comunidade foi representada por 10 moradores (E8a, E8b, E8c, E8d, E8e, E8f, E8g, E8h, E8i, E8j) do município de Beberibe, situado na costa leste do estado do Ceará. As entrevistas não foram previamente agendadas e foram realizadas com residentes próximos às usinas eólicas. O roteiro de entrevistas avaliava as opiniões dos moradores sobre a instalação dos parques eólicos, como ocorreu o envolvimento com as empresas geradoras, notadamente E1, desde a instalação até a operação.

O material coletado nas entrevistas foi transcrito e submetido à análise de conteúdo, realizada em três fases: pré-análise, análise e tratamento por meio de interpretação (BARDIN, 1994). Na pré-análise, o material selecionado obedeceu aos critérios de representatividade e relevância. Na fase de análise, os dados foram organizados em categorias 
Mônica Cavalcanti Sá de Abreu, Alexandra Alencar Siebra, Larissa Teixeira da Cunha \& Sandra Maria dos Santos

que permitissem diferenciar e reagrupar os elementos da pesquisa. Os resultados das entrevistas foram agrupados nas categorias: percepções e pressões dos stakeholders, e fatores políticos e tecnológicos.

A categoria "percepções e pressões dos stakeholders" compõem as exigências e a atuação das partes interessadas para o avanço da energia eólica no Estado do Ceará. Na categoria "políticas públicas" foram identificadas: o papel das políticas públicas, em especial do PROINFA, dos incentivos fiscais e financiamentos de parques eólicos. Para a categoria "fatores tecnológicos" foram identificados os investimentos, papel da tecnologia no avanço do setor eólico e a influência da curva de aprendizado nos projetos das usinas eólicas.

A relação entre os dados obtidos e o agrupamento teórico deu sentido à interpretação. A análise aconteceu por meio da proximidade do conteúdo com as respostas dos grupos que refletiam as categorias definidas. Os resultados alcançados na pesquisa permitem identificar fatores que afetam a implantação dos parques eólicos, tomando o Estado do Ceará como unidade de estudo.

\section{RESULTADOS}

\subsection{Percepções e Pressões dos Stakeholders}

Durante as entrevistas, foram encontrados elementos que permitem representar a atuação das partes interessadas nas empresas geradoras de energia eólica, conforme apresentado na Figura 1. Tomando por base o modelo definido por Fassin (2009), a comunidade, o fornecedor de tecnologia e os concorrentes são denominados de stakeholders. O papel de stakewatcher é fracamente exercido pela ONG. Os stakekeepers, evidenciados nas entrevistas, foram o governo (na figura do poder executivo), o banco e o investidor, os quais exercem influência ao impor regras e viabilizar recursos financeiros para a construção dos parques eólicos.

REAd | Porto Alegre - Edição 78 - Nº 2 - maio/agosto 2014 - p. 274-304 
Fatores determinantes para o avanço da energia eólica no Estado do Ceará frente aos desafios das mudanças climáticas

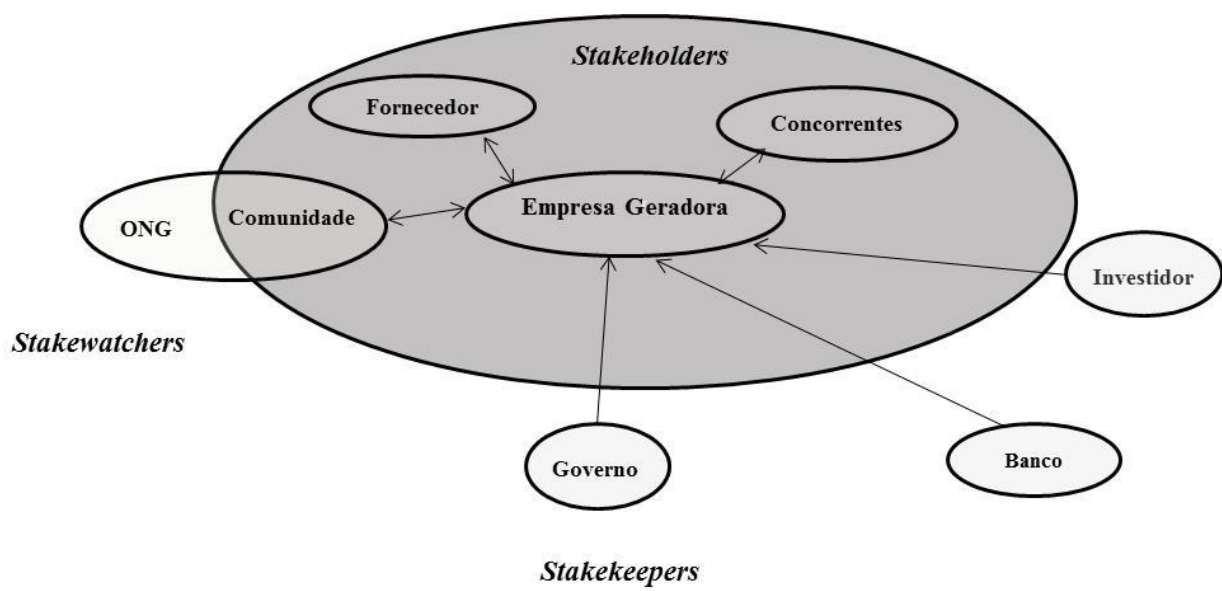

Figura 1 - Interação dos atores entrevistados com a empresa geradora de energia eólica (E1). Fonte: Adaptado do modelo de Fassin (2009), tomando por base as entrevistas.

Analisando o papel dos stakeholders - comunidade, fornecedor e concorrentes observam-se diferentes interesses e formas de pressão. As empresas entrevistadas (E1, E4a e E4b) enfatizaram a importância de ouvir as demandas das comunidades localizadas próximas aos parques eólicos em operação e/ou em construção, uma vez que resistências da comunidade podem inviabilizar a implantação dos parques. A gerente de meio ambiente da empresa geradora de energia (E1) relatou que antes da implantação dos parques foram feitas avaliações arqueológicas, restaurações de uma igreja antiga da comunidade e, inclusive, foi pedida uma avaliação do Instituto do Patrimônio Histórico e Artístico Nacional (IPHAN), com o intuito de ver se uma igreja poderia ser tombada.

No começo da implantação do parque eólico no Município de Beberibe ocorreram problemas com a comunidade. Os moradores (E8d, E8j e E8c) relataram a ocorrência de rachaduras nas estruturas das casas próximas à construção dos parques e dificuldade de acesso às dunas para se chegar à praia. Porém, a empresa E1, em conjunto com Governo do Estado do Ceará, assumiu uma série de compromissos. Foram fornecidos cursos de capacitação, profissionalizantes e esportivos, como capoeira e corte e costura, melhorando a relação com a comunidade, conforme afirmam os entrevistados:

No começo a gente teve algumas duvidas e ficamos muito brabos por causa da confusão, sujeira, a s casas rachavam e muita poeira dos caminhões. Mas depois eles prometeram (governo) que ajeitava e ajeitaram quase tudo. (E8a)

Pelo menos eles sempre que estavam lá conversavam e anotavam o que a gente dizia, reclamava né? e ia fazendo devagarzinho. Além da beleza, eles deram cursos e melhoraram algumas casas que ficaram ruim depois da construção. Nós entendemos que era importante para o planeta. (E8i)

REAd | Porto Alegre - Edição 78 - N² 2 - maio/agosto 2014 - p. 274-304 
Mônica Cavalcanti Sá de Abreu, Alexandra Alencar Siebra, Larissa Teixeira da Cunha \& Sandra Maria dos Santos

A aceitação da comunidade tem, portanto, um forte impacto nas decisões estratégicas dos produtores de energia eólica e dos fornecedores de tecnologia. Existem diversas reações decorrentes da instalação de um parque eólico. Por exemplo, os moradores do município de Beberibe percebem a turbina eólica como um símbolo de energia limpa. Esta aceitação ocorre em resposta aos esforços das empresas produtoras e do Governo Estadual na conscientização dos benefícios do parque, conforme afirma o superintendente da secretaria estadual de meio ambiente (E6).

As informações fornecidas pelos moradores que residem próximo ao Parque Eólico instalado no município de Beberibe (CE), e pela ONG (E7), que atua na região, demonstram que o apoio da comunidade às instalações dos parques eólicos requer um amplo diálogo envolvendo, principalmente, as empresas geradoras e o governo:

A gente sabe que o governo está por trás desse monte de torre de catavento, mas se for para ter energia e não acabar com o nosso sustento como o peixe. A gente tem medo de colocar as torres na água, aí sim, ia ficar complicado de pescar né? (E8d).

A legislação e a fiscalização são primordiais para as empresas investirem em energias renováveis São fortes indicadores, porém muitos também apreciam o "marketing verde", ou seja, querem mostrar que são "sustentáveis" quando na verdade não entendem tal conceito (E7).

Nas entrevistas com representantes da comunidade, observou-se a necessidade de conscientização sobre os impactos econômicos, ambientais e sociais dos parques eólicos. Esta conscientização requer uma melhoria no nível de escolaridade da comunidade com a criação de canais de comunicação, segundo informações dos moradores.

A gente percebeu que no começo as torres eram mais barulhentas e depois mudou alguma coisa e elas ficaram menos barulhentas. Também ouvimos dizer que seriam mais de cem torres, mas quando conversamos com os engenheiros eles disseram que antes era preciso mais em quantidade para ter a mesma quantidade de energia, melhor né? (E8f)

No caso dos concorrentes, o setor de energia eólica caracteriza-se ainda por uma forte parceria, em virtude, da necessidade de nacionalização dos equipamentos, da pressão conjunta por políticas públicas de incentivo à geração de energia eólica, e a garantia da compra da energia pelo governo. Conforme informaram os entrevistados E1, E4a e E4b, as empresas atuam na promoção de eventos com foco no fortalecimento da cadeia de suprimento, por exemplo, o Brazil Wind Power e o All About Energy.

O fornecedor de tecnologia relata, também, que existe um diálogo constante com os órgãos ambientais. A empresa contribui com o esclarecimento dos analistas da SEMACE

REAd | Porto Alegre - Edição 78 - N² 2 - maio/agosto 2014 - p. 274-304 
Fatores determinantes para o avanço da energia eólica no Estado do Ceará frente aos desafios das mudanças climáticas

sobre os processos de construção de um parque eólico, mostrando os cuidados e até procurando acabar com alguns mitos com relação a essa questão, na tentativa de reduzir o prazo de obtenção das licenças ambientais.

Conforme afirma o entrevistado E1, as ONGs ainda não acompanham sistematicamente os temas relacionados às questões climáticas e a segurança energética. $\mathrm{O}$ fornecedor de tecnologia afirma, no entanto, que a mídia tem um papel relevante para criar uma imagem positiva das empresas do setor eólico.

A gente sofre pressão da comunidade e o Brasil que é o país que tem maior índice de energias limpas, a gente não pode ir hoje na contramão dessa realidade. Então esse papel da mídia é muito importante e ao mesmo tempo a mídia contribui do ponto de vista de informações estratégicas do ponto de vista econômico, então a gente vê muita notícia de investimento, isso faz com que se crie uma agenda positiva nessa área de renováveis. (E2)

As empresas entrevistadas (E1, E4a e E4b) citaram o crescimento do número de investidores na geração de energia eólica, com a abertura de novas empresas registradas na ANEEL. Em muitos casos são sociedades de propósito específico - SPE, que buscam diversificar seus negócios, através de investimentos em energia limpa. Para o investidor (E3), a redução do risco é um fator determinante para a decisão de novos investimentos.

A redução do risco de gestão, neste caso, é mais no sentido de diversificação do negócio, pois olhando a gestão de um negócio como um todo não tem risco, mas a possibilidade de você ter outros negócios dentro do seu portfólio. (E1)

Quando você não tem energia disponível ninguém nem investe, e pensando nisso o potencial do Ceará não foi explorado totalmente, inclusive nós temos pesquisas de ventos com viabilidade de uso em eólica não só no litoral, mas também no nosso interior, já tem vários projetos sendo desenvolvidos nas regiões no interior do Ceará. (E3)

O investidor afirma que a questão climática apresenta-se como oportunidade de negócio. As empresas observam um aumento ao acesso a fontes de financiamento, e a melhoria de sua reputação a partir da implantação de projetos de redução de gases de GEE. Com relação ao risco regulatório, quando as empresas se antecipam a possíveis regulações, elas podem obter vantagens competitivas através da alocação adequada de recursos humanos e tecnológicos, fato evidenciado na entrevista.

No momento em que não houver a restrição, a concorrência vem, os preços vão ser baixos e fatalmente você não vai ganhar dinheiro. Então nós aprendemos a conviver em relação à legislação limitante em termos de novos entrantes no mercado e nós tiramos vantagem disso. (E3) 
Mônica Cavalcanti Sá de Abreu, Alexandra Alencar Siebra, Larissa Teixeira da Cunha $\&$ Sandra Maria dos Santos

O entrevistado (E5) afirma ainda que o banco exige a realização do monitoramento ambiental nos parques eólicos. Existem, aproximadamente, 15 pontos de coleta da SEMACE em todo o Estado do Ceará e equipes de biólogos que mensalmente acompanham a fauna, flora, movimentação de sedimentos, qualidade da água e qualidade dos efluentes. No entanto, o analista de crédito bancário evidencia poucas exigências relacionadas com práticas capazes de mitigar os efeitos da mudança climática nos projetos financiados pelo banco, ao afirmar que:

A gente está procurando estimular as empresas a agregar em seus empreendimentos
ações para enfrentar a questão das mudanças climáticas. Entretanto, apesar de o
Banco ser extremamente sensível às questões ambiental e da energia renovável, só
tem como financiar projetos que não apresentem indicadores desfavoráveis ao
financiador, por ser uma instituição financeira e atuar sob os disciplinamentos do
Banco Central, visando à questão da segurança do sistema econômico.

Outros fatores influenciam as empresas a investirem no setor eólico. Ressalta-se o crescimento do consumo de energia, os contratos com a Eletrobrás que minimizam os riscos e ampliam as garantias. Existe, portanto, um interesse de todos os participantes do setor eólico em consolidar o investimento no Estado do Ceará, desde que sejam oferecidas garantias que minimizem os riscos. Os investidores observam que existem garantias, de longo prazo, estabelecidas por meio de políticas públicas, que diminuem os riscos e atendem às expectativas por resultados financeiros.

\subsection{Aspectos relacionados com as Políticas Públicas}

Oportunidades de negócios foram geradas por políticas públicas de incentivo à geração de energia eólica, somada às pressões dos stakeholders para o aumento da utilização de recursos renováveis. Aliado aos incentivos federais, o governo do estado do Ceará, com o objetivo de aumentar a competitividade do estado nesse segmento, publicou o Decreto $\mathrm{n}^{\circ}$ 30.230, de 17 de junho de 2010 (CEARÁ, 2010), que garante às empresas do setor eólico uma isenção de ICMS que pode chegar a 74\%. Desta forma, a participação da energia eólica foi potencialmente incentivada por políticas públicas, conforme afirmam as empresas geradoras:

O Governo já fez o papel dele, já deu o primeiro passo e o mercado agora tem como se sustentar sozinho, já está maduro o suficiente. Não que o Governo deva agora se retrair, mas a tendência é essa. (E1)

A continuidade dos leilões é de suma importância. São vários passos bem difíceis. Primeiro você tem que fazer todo um processo pra concorrer ao leilão. Depois daí se você ganha é outro processo pra começar o empreendimento mais outro difícil para você conseguir funcionar. (E1) 
Fatores determinantes para o avanço da energia eólica no Estado do Ceará frente aos desafios das mudanças climáticas

A expectativa maior está no que o governo fará para garantir ao Brasil energia suficiente que garanta o desenvolvimento e nesse sentido a energia renovável como a eólica se configura como uma opção. O Brasil contou inclusive com a crise na Europa, em que muitos fabricantes optaram por comercializar seus equipamentos para o Brasil. (E4b)

A perspectiva de um preço mais competitivo da energia eólica foi considerada por todos os respondentes como um fator determinante nas estratégias das empresas do setor de energia eólica. O Brasil vem apresentando um crescimento da sua capacidade instalada em decorrência dos leilões de fontes alternativas de energia. Esta afirmativa é corroborada pelo analista de crédito bancário (E5):

O Banco fez um trabalho em sintonia com os marcos regulatórios do governo Brasileiro. Basicamente, num primeiro momento, com o PROINFA, que era o programa de governo que garantia os preços, e agora nos leilões, onde você já tem mais uma prática de mercado que tem funcionado e tem dado bons retornos.

Nesse último leilão muitas empresas fabricantes de equipamento estavam presentes como sócios nas SPEs (Sociedades de Propósito Específico), porque é uma forma de elas viabilizarem os projetos e ganharem, mas não na venda de equipamento, mas na comercialização da energia que elas vão gerar.

Bancos, como o BNB, oferecem programas de financiamento dentro da linha do Fundo Constitucional de Financiamento do Nordeste (FNE), chamados FNE Verde. Observase que as participações das usinas eólicas na composição da matriz energética brasileira tornaram-se mais expressivas, a partir das linhas de financiamento de longo prazo, conforme explica o analista de crédito bancário:

A ação do governo é uma ação de fortalecimento, de mobilização, de parceria. Existia há dez anos zero em termos relativos de geração de energia eólica na matriz energética, e na hora que o BNB e o BNDES passaram a efetuar os financiamentos, passou-se a perceber números bastante significativos de contribuição de energia renovável e, dentro dela, a eólica para a matriz energética brasileira.

Segundo o fornecedor de tecnologia (E2), o governo está tentando ampliar benefícios sociais oriundos da implantação de parques eólicos. Contudo, existem riscos associados a continuidade das políticas públicas de incentivo a geração de energia eólica que devem ser considerados, conforme relatam os entrevistados das empresas geradoras de energia:

O maior risco na realidade era saber se todo o investimento que a gente estava fazendo ia ter continuidade após o PROINFRA. A principal vocação do governo seria dar as condições com relação aos incentivos econômicos. (E1)

As questões regulatórias e o fato de que os leilões promovidos pelo Governo Federal não propiciarem uma Taxa de Retorno de Investimento (TIR - IRR) interessante para a empresa e seus investidores, associado à indisponibilidade de tecnologia

REAd | Porto Alegre - Edição 78 - N 2 - maio/agosto 2014 - p. 274-304 
Mônica Cavalcanti Sá de Abreu, Alexandra Alencar Siebra, Larissa Teixeira da Cunha $\&$ Sandra Maria dos Santos

adequada (aerogeradores) para melhor aproveitamento da classe de vento que ocorre na região dos projetos. (E4a)

Uma questão relevante trata da infraestrutura de redes de distribuição de energia elétrica que parte do governo e, sobretudo, requer uma legislação que garanta a segurança jurídica aos investidores. O problema das linhas de transmissão pode vir a impactar os futuros leilões de energia e reduzir a competitividade do setor. Esta observação é corroborada pela gerente ambiental de uma das empresas geradoras de energia entrevistada.

Porque a gente não tem, por exemplo, a questão das ligações. Quem recebe a energia que você produz? As subestações. Ainda não tem uma rede que vai suprir todas essas demandas.

Uma coisa que já foi colocada na questão do governo é a criação de linhas de transmissão, já percorrendo um bom trecho do litoral para poder facilitar. A gente produz energia em Aracati e vai lá pra Russas. É uma distância grande se você for comparar com os parques europeus. Que você tem subestações de recebimento de energia a cada esquina. Exagerando, mas é bem diferente a estrutura (E1).

Não bastam apenas incentivos fiscais para alavancar o setor eólico. É preciso superar também os obstáculos burocráticos que impedem o cumprimento dos prazos e atrapalham o processo de obtenção das licenças ambientais. As fiscalizações nos empreendimentos eólicos procuram verificar o cumprimento das condicionantes das licenças ambientais e combater a poluição. Conforme afirmam os entrevistados:

\footnotetext{
As empresas que possuem processos ou produtos que gerem riscos (internos ou externos extra muros), estas são responsáveis pelos mesmos e deverão minimizar os mesmos por meio de salva-guardas e fazer Estudos de Análises de Riscos - EAR, bem como ter um Plano de Gerenciamento de Riscos - PGR. (E6)

Houve um desentendimento e sim uma falta de compreensão de alguns órgãos do estado porque eles estavam pedindo uma licença dupla. Duas licenças prévias, duas licenças de instalação para um mesmo empreendimento. (E1)
}

Nesse sentido, o analista de crédito (E5) e o fornecedor de tecnologia corroboram com a gerente ambiental (E1) de que existem algumas divergências na avaliação dos impactos ambientais e nos seus procedimentos de controle e mitigação. $\mathrm{O}$ atraso na liberação da licença ambiental impacta na operação dos parques eólicos no estado do Ceará.

\subsection{Fatores Tecnológicos}

As primeiras empresas que investiram no setor eólico (first mover) tiveram que lidar com os altos custos dos investimentos em equipamentos e a ausência de infraestrutura. Segundo o entrevistado (E2), os fornecedores de tecnologia possuem uma estreita parceria 
Fatores determinantes para o avanço da energia eólica no Estado do Ceará frente aos desafios das mudanças climáticas

com as empresas geradoras de energia eólica. Esta parceria ocorre por meio de instalação de fábricas de equipamentos com investimentos para atender às especificidades do setor eólico do Brasil, diminuindo, portanto, o risco do negócio. A evolução tecnológica do aerogeradores apresenta-se como um dos fatores mais citados nas entrevistas. Conforme explica o fornecedor de tecnologia (E2) e a gerente ambiental de uma das empresas geradoras de energia entrevistada (E1):

Num primeiro momento era complicado competir com essas formas de energia que já estavam implantadas na matriz energética brasileira em função de não ter uma cadeia produtiva nacionalizada, muitos equipamentos importados, não ter uma infraestrutura na cadeia produtiva em larga escala, isso onerava o preço (E1)

A capacidade das turbinas cresceu de $50 \mathrm{~kW}$ para $5 \mathrm{MW}$, sendo que, nos anos 80, as pás mediam 15 metros de diâmetro contra os 124 metros atuais, o que permitiu que os parques eólicos constituíssem uma alternativa contundente para diversos níveis de demanda" (E2).

Para o analista de crédito (E5), outro fator decisivo reside na baixa complexidade da operação de um parque eólico. O principal risco operacional ocorre na montagem dos parques. Porém, depois que o parque é montado, existe o seguro dos equipamentos, o que garante seu desempenho. Segundo o fornecedor (E2), as soluções técnicas, desenvolvidas no Brasil ("tropicalizar a tecnologia"), garantem a continuidade dos investimentos no setor. As principais questões colocadas pelos entrevistados envolvem a segurança no investimento, o apelo ambiental pelo uso de energia renovável e a nacionalização da tecnologia.

É um dos poucos investimentos no Brasil em que você pode fazer um Project Finance, quer dizer a própria venda da energia para a Eletrobrás é a garantia, esse contrato é a garantia para conseguir o recurso para o investimento. (E3)

No início era um assunto muito pouco explorado, mas eu rapidamente entendi que aquilo só iria se solidificar dentro da matriz energética brasileira por conta do próprio apelo do planeta, a necessidade de combater os efeitos de gases, meio ambiente, essa coisa toda. E considerando que o Brasil é um país em pleno desenvolvimento. (E2)

Eles trouxeram este "know-how" e tem sido uma troca de informações, agora sobretudo, o papel nosso na construção civil é você colocar parques eólicos em locais que não tenha nenhuma infraestrutura e você criar meios para que se tenha nesses locais infraestrutura que garantam a qualidade de um processo construtivo como um todo em condições até melhor que Europa e Estados Unidos. (E2)

Para o investidor (E2), com o aumento do número de fornecedores, os custos das turbinas estão diminuindo. A evolução do padrão tecnológico dos aerogeradores apresenta-se como determinante para a operação dos parques eólicos. No caso do Estado do Ceará, os ventos são predominantemente calmos e de boa velocidade, atingindo em torno de 8 a 9 metros por segundo.

REAd | Porto Alegre - Edição 78 - N² 2 - maio/agosto 2014 - p. 274-304 
Mônica Cavalcanti Sá de Abreu, Alexandra Alencar Siebra, Larissa Teixeira da Cunha $\&$ Sandra Maria dos Santos

Contudo, os equipamentos importados foram projetados para ventos de rajada, com baixa velocidade (em torno de 4 a 5 metros por segundo) ou de alta velocidade (cerca de 16 a 17 metros por segundo). Outro problema com os aerogeradores envolve a corrosão, que exige uma manutenção periódica dos equipamentos, e a necessidade de investimentos em tecnologia de materiais.

Para o fornecedor de tecnologia (E2), as soluções técnicas apresentadas com clareza aos clientes acabam por gerar credibilidade. A respeito dessas soluções, a gerente ambiental da geradora de energia eólica (E1) enfatiza que é de extrema importância ampliar a capacidade de previsão climática e de estimar o potencial dos ventos. Outro fator evidenciado nas entrevistas recai sobre a qualificação da força de trabalho para estarem aptos a atenderem à evolução tecnológica, além de contarem com uma estrutura física adequada para atender à demanda. De acordo com o fornecedor de tecnologia (E2):

Nós temos aqui o que a gente chama de cadeia multiplicadora, sempre aqueles que estão há mais tempo na empresa, que tem um "know-how" do negócio, estão fazendo treinamento em novos colaboradores, então com isso a gente cria uma estrutura de mão-de-obra qualificada.

O fornecedor de tecnologia (E2), o investidor (E3) e a gerente ambiental da empresa geradora de energia (E1) concordam que são executados planejamentos sistemáticos que priorizam ações ambientalmente responsáveis. São adotadas as seguintes práticas: retirada de resíduos da obra, capacitação da própria comunidade para trabalho na construção do parque, destino dos materiais não utilizados para a comunidade, mantendo, principalmente, o diálogo.

No caso das práticas de inovação para mitigar os efeitos das emissões de GEE, a empresa E1 ressalta apenas a realização de investimentos na melhoria da eficiência operacional. A entrevistada enfatiza que o impacto ambiental da geração de energia eólica, por meio de emissões de GEE é baixo, e, portanto, não precisaria de um controle intenso das atividades operacionais, ao afirmar que:

É muito difícil você mensurar o impacto porque a essência da nossa atividade é uma matriz energética limpa, então não vou dizer que a gente não vai emitir nenhum poluente porque é mentira. Mas se você for comparar com as outras fontes, inclusive a hidráulica, a nossa emissão é mínima. A gente usa combustível fóssil no nível mínimo, nosso gerador é um gerador de reserva, acho que nunca foi utilizado.

Mesmo estando previsto no sistema de controle controlar a emissão, não é uma prioridade em virtude da baixa emissão da atividade. Nossos aerogerados com sua qualidade diminuiram de 30 para 1 o número de torres para gerar a mesma energia o que diminui transporte, fabricação e diminuía toda a pegada de carbono desde a fabricação até a montagem

REAd | Porto Alegre - Edição 78 - Nº 2 - maio/agosto 2014 - p. 274-304 
Fatores determinantes para o avanço da energia eólica no Estado do Ceará frente aos desafios das mudanças climáticas

Os entrevistados (E1, E2 e E3) concordam com a necessidade de se investir em práticas de compensação, por meio de investimentos em ativos de empresas com baixa emissão de GEE. A respeito da possibilidade de venda de crédito de carbono pelas empresas do setor eólico, o fornecedor (E2) e o investidor (E3) ressaltam nas entrevistas que é provavelmente um mercado promissor, embora, não realizem estes investimentos. Os entrevistados observam a atuação de empresas europeias e americanas, que estimulam o mercado de crédito de carbono para que suas fábricas possam continuar a produzir, e inevitavelmente a poluir, desde que invistam em energia limpa.

Para a gerente ambiental da empresa geradora de energia (E1), o foco das atividades da empresa envolve a valorização do patrimônio e harmonização das atividades empresariais com o meio ambiente, com a cultura e com a comunidade vizinha. Relata ainda, que não apenas se aproveita a imagem de “empresa limpa e responsável”, mas patrocinam eventos socioambientais.

\section{DISCUSSÃO DOS RESULTADOS}

O estudo aponta que o avanço do setor eólico é influenciado por pressões dos stakeholders, políticas públicas e fatores tecnológicos. Conforme exposto no quadro 2, estes fatores geram condições favoráveis ou não à decisão de instalação de parques eólicos no Estado do Ceará, merecendo, assim, destaque na discussão. Os entrevistados confirmam que os acionistas e investidores se configuram como os stakeholders de maior influência nas decisões de investimentos em parques eólicos.

As empresas do setor de energia eólica buscam oportunidades de investimento com um baixo risco financeiro. Elevados investimentos no setor de energia eólica trazem os benefícios de ampliar a escala e reduzir os custos tecnológicos. Barradale (2010) relata que, para que os empresários invistam na produção da energia eólica, são necessárias garantias, em longo prazo, que diminuam seus riscos. Para que seja competitivo o investimento em energia eólica, deve-se atender às expectativas de resultados dos investidores.

Estudos realizados por Nogueira (2011) demonstram que os acionistas e investidores estão preocupados, principalmente, com os riscos financeiros. No Brasil o sucesso dos leilões para fornecimento de energia de reserva foi alcançado em virtude dos preços competitivos sem a adoção dos mecanismos convencionais, tais como o sistema feedin. Este mecanismo consiste em uma política pública destinada a acelerar o investimento em 
Mônica Cavalcanti Sá de Abreu, Alexandra Alencar Siebra, Larissa Teixeira da Cunha \& Sandra Maria dos Santos

energias renováveis, por meio da oferta de contratos de longo prazo para produtores desse tipo de energia.

Quadro 2 - Fatores determinantes para o avanço do setor eólico

\begin{tabular}{|c|c|c|c|}
\hline FATORES & ELEMENTOS & CONDIÇÃO & INFLUÊENCIA \\
\hline \multirow{5}{*}{$\begin{array}{l}\text { Pressão dos } \\
\text { Stakeholders }\end{array}$} & Disponibilidade de financiamento & Existente & Favorável \\
\hline & $\begin{array}{l}\text { Exigências ambientais para a redução das } \\
\text { emissões de GEE }\end{array}$ & Ausente & Favorável \\
\hline & $\begin{array}{l}\text { Atrasos no processo de licenciamento } \\
\text { ambiental }\end{array}$ & Existente & Desfavorável \\
\hline & Colaboração entre empresas competidoras & Existente & Favorável \\
\hline & Riscos de reações adversas da comunidade & Existente & Desfavorável \\
\hline \multirow{6}{*}{ Políticas Públicas } & Incentivos fiscais através do PROINFRA & Existente & Favorável \\
\hline & $\begin{array}{l}\text { Competitividade do preço do KWh nos leilões } \\
\text { da ANEEL }\end{array}$ & Existente & Favorável \\
\hline & Criação de câmaras setoriais & Existente & Favorável \\
\hline & $\begin{array}{l}\text { Realização de leilões para a aquisição da } \\
\text { energia renovável pelo governo }\end{array}$ & Existente & Favorável \\
\hline & $\begin{array}{l}\text { Garantia de Segurança Jurídica aos } \\
\text { investidores e acionistas }\end{array}$ & Existente & Favorável \\
\hline & $\begin{array}{l}\text { Falhas na integração da geração eólica nas } \\
\text { redes de transmissão e }\end{array}$ & Existente & Desfavorável \\
\hline \multirow{7}{*}{ Tecnológicos } & Adequação tecnológica ao padrão dos ventos & Existente & Favorável \\
\hline & Melhoria operacional dos aerogeradores & Existente & Favorável \\
\hline & $\begin{array}{l}\text { Práticas comercialização de créditos de } \\
\text { carbono }\end{array}$ & Ausente & Favorável \\
\hline & $\begin{array}{l}\text { Localização geográfica dos fornecedores de } \\
\text { tecnologia }\end{array}$ & Existente & Favorável \\
\hline & $\begin{array}{l}\text { Desenvolvimento de tecnologia com foco } \\
\text { redução das emissões de GEE }\end{array}$ & Ausente & Favorável \\
\hline & $\begin{array}{l}\text { Desenvolvimento de tecnologia com foco na } \\
\text { compensação das emissões de GEE }\end{array}$ & Ausente & Favorável \\
\hline & $\begin{array}{l}\text { Investimentos para ampliação da escala e } \\
\text { redução de custos }\end{array}$ & Existente & Favorável \\
\hline
\end{tabular}

$$
\text { Fonte: Elaborado a partir das entrevistas }
$$

A pesquisa revelou que a aceitação da comunidade representa um forte impacto na geração de energia eólica. Terciote (2002) descreve em seus estudos, que existe uma subjetividade na reação provocada por um parque eólico, pois a comunidade poderá vir a perceber a turbina eólica como um símbolo de energia limpa, desde que devidamente conscientizada dos seus benefícios.

A pesquisa confirmou também os esforços do governo na concessão de incentivos fiscais e subsídios a implantação de parques eólicos. O governo, através do PROINFA, foi capaz de tornar o setor atrativo aos novos investidores, garantindo que os parques eólicos entrem em operação e contribuam com a segurança energética, viabilizando a participação da energia eólica na matriz energética do país. Os estudos de Saidur et al. (2010) corroboram 
Fatores determinantes para o avanço da energia eólica no Estado do Ceará frente aos desafios das mudanças climáticas

com estes resultados, e afirmam que as políticas públicas devem proteger os investimentos em energia eólica e garantir a segurança energética.

A influência das políticas públicas é evidenciada em ações como as implantadas no Estado do Ceará. A integração dos diversos segmentos da cadeia produtiva de energia eólica ocorreu com a publicação da Portaria nº 106/2009 e a criação da Câmara Setorial de Energia Eólica do Estado do Ceará - CS Eólica (ADECE, 2010). A CS Eólica é composta por 24 instituições, entre entidades privadas, organizações não governamentais e órgãos públicos e privados relacionados com a cadeia produtiva de energia eólica.

A atuação das câmaras setoriais repousa, principalmente, na identificação de oportunidades e entraves impeditivos ao desenvolvimento do setor de energia eólica no Estado do Ceará. Deve, então, articular agentes públicos e privados e definir as ações prioritárias de interesse comum, com o objetivo de atuar de forma integrada com os diferentes segmentos envolvidos (ADECE, 2010).

Conforme observado nas entrevistas, incentivar os leilões e adquirir energia renovável a um preço pré-definido podem configurar-se medidas eficazes de incentivo a uma rápida implantação de energias renováveis. De acordo com Alishahi, Moghaddam e Sheikhel-Eslami (2011), estas políticas públicas criam condições propícias para o rápido crescimento do mercado de energia renovável. Mathiesen, Lund e Karlsson (2011) afirmam que a adoção de políticas para aumentar a quota das energias renováveis também representa uma significativa resposta às mudanças climáticas.

Para as empresas pesquisadas, o debate se concentra sobre os custos da utilização de energia renovável e os investimentos necessários em infraestrutura e tecnologia. De acordo com Vine (2008), as regras políticas devem definir os custos associados aos projetos de geração de energia. Estes custos devem ser alocados e a regulamentação que se faz necessária para promover a integração entre as estratégias empresariais e os incentivos governamentais que respondam à ameaça de alterações climáticas.

Sob o aspecto tecnológico, Alves (2010) afirma que as regiões Nordeste e Norte apresentam os melhores potenciais para o desenvolvimento da energia eólica no Brasil. A força e a constância dos ventos, praticamente durante todo o ano, principalmente, na costa nordestina entre o Rio Grande do Norte e o Ceará, foram fatores ressaltados por todos os entrevistados. Além das favoráveis condições ambientais e da pequena distância ao centro de consumo da energia, a costa nordestina conta, também, com a proximidade dos fornecedores dos equipamentos. Além do potencial dos ventos nessas regiões, o investimento em energia 
Mônica Cavalcanti Sá de Abreu, Alexandra Alencar Siebra, Larissa Teixeira da Cunha $\&$ Sandra Maria dos Santos

eólica foi norteado, também, por meio da participação do Produtor Independente de Energia (PIE), devido a flexibilidade proporcionada pela atual legislação do setor elétrico.

$\mathrm{O}$ rápido avanço tecnológico é apontado como um dos principais fatores para investimentos no setor, levando a redução dos preços das turbinas e dos custos de manutenção e de operação. Este avanço contribuiu para um aumento da eficiência na geração de energia através de designs mais avançados, lâminas largas e hubs mais altos. Nesse sentido, o estado do Ceará se destaca com a instalação, em 2012, de uma fábrica de aerogeradores, o que facilita a construção dos futuros parques eólicos, diminuindo os custos logísticos decorrentes do transporte das pás e dos hubs (BRASIL, 2012).

A influência dos incentivos fiscais e evolução do padrão tecnológico identificada nas entrevistas confirmam o discurso de Bessant e Tidd (2009). Os estudos de Bermann (2008) relatam a importância da análise do impacto do uso da energia renovável e do acompanhamento dos investimentos, definidos por políticas públicas. Existe uma tendência das empresas considerarem as questões macroeconômicas, como o preço, além das políticas internacionais, a estrutura e a regulação da indústria como influências importantes na decisão de novos investimentos.

\section{CONSIDERAÇOES FINAIS}

O Brasil é um país de um expressivo potencial eólico, porém, ainda não possui parques e uma infraestrutura de redes de transmissão e distribuição de energia que garantam a consolidação do setor. A pesquisa analisou a influência que os stakeholders e os fatores políticos e tecnológicos exercem no avanço da energia eólica, tomando o Estado do Ceará como unidade de estudo.

A pressão dos stakeholders revela-se fundamental para a consolidação da contribuição da energia eólica na matriz energética nacional. Os acionistas e investidores buscam segurança jurídica e operacional, como mecanismos para a redução do risco financeiro. As empresas de energia eólica contam com os incentivos públicos para a geração de energias renováveis, por meio do PROINFA. Preços mais competitivos no mercado de energia do KWh produzido são alcançados nos leilões promovidos pela ANEEL, o que diminui significativamente os riscos dos investimentos.

Paralelamente, os governos estaduais oferecem incentivos buscando atingir toda a cadeia de suprimento, desde a geração de energia, fabricação de equipamentos e fornecimento 
Fatores determinantes para o avanço da energia eólica no Estado do Ceará frente aos desafios das mudanças climáticas

de serviços. O aumento do número de parques eólicos em implantação no país reduzem os custos de transação. As empresas trabalham, em conjunto com o governo do estado do Ceará, em direção a uma aceitação da comunidade sobre a implantação dos parques eólicos.

A questão da mudança climática pode agir com um elemento catalisador para as empresas de geração de energia renováveis, criando um mercado favorável à implantação dos parques eólicos. Destacam-se os investimentos na melhoria da eficiência dos aerogeradores, no entanto, as empresas não vislumbram oportunidades de investimento em projetos de redução de GEE. As empresas geradoras de energia reconhecem o potencial mercadológico da energia eólica com a associação a imagem de energia limpa e sustentável.

As limitações deste trabalho devem ser reconhecidas, pois envolvem, principalmente, entrevistas com participantes que atuam no setor de energia eólica no Estado do Ceará. Desse modo, não pode configurar o cenário da energia eólica no Brasil. Recomenda-se que sejam realizadas pesquisas com uma amostra maior, englobando outras empresas geradoras de energia no país, integrantes da cadeia de suprimento e outras partes interessadas, como a ANEEL e a mídia. A segunda limitação envolve um estudo estático, ou seja, não é possível capturar mudanças nas práticas adotadas e a influência destes fatores na competitividade e sustentabilidade do setor de energia eólica ao longo do tempo.

Como contribuição, o trabalho reforça a importância do incentivo governamental para a geração da energia eólica, por meio de políticas públicas que ampliem os investimentos no setor e garantam a segurança jurídica e operacional no curto prazo. No longo prazo, é vital que o Governo atue na redução das falhas na integração da geração eólica nas redes de transmissão e

Os incentivos governamentais concedidos devem, no entanto, explicitar compromissos com adoção de medidas capazes de mitigar os impactos da mudança climática. $\mathrm{O}$ estágio atual de incertezas com relação à segurança energética e alterações no clima, exigem uma ampla participação de todos os atores envolvidos na busca de soluções que gerem benefícios econômicos, ambientais e sociais.

\section{AGRADECIMENTOS}

Aos revisores, por suas valiosas contribuições para a versão final deste artigo e ao CNPq, pelo financiamento ao projeto de pesquisa. 
Mônica Cavalcanti Sá de Abreu, Alexandra Alencar Siebra, Larissa Teixeira da Cunha $\&$ Sandra Maria dos Santos

\section{REFERÊNCIAS}

ADECE. AGÊNCIA DE DESENVOLVIMENTO DO ESTADO DO CEARÁ. Atração de Investimentos no Estado do Ceará: mapa territorial de parques eólicos. Ceará, 2010.

ALISHAHI, E.; MOGHADDAM, M. P.; SHEIKH-EL-ESLAMI, M. K. An investigation on the impacts of regulatory interventions on wind power expansion in generation planning. Energy Policy, v. 39, p. 4614-4623, 2011.

ALVES, J. J. A. Análise regional da energia eólica no Brasil. Revista Brasileira de Gestão e Desenvolvimento Regional, v. 6, n. 1, p. 165-188, 2010.

AGÊNCIA NACIONAL DE ENERGIA ELÉtriCA. ANEEL. Portal Acompanhamento de Autorização das Centrais Geradoras Eólicas. Disponível

em:<http://www.aneel.gov.br/area.cfm?idArea=40\&idPerfil=2>. Acesso em: 13 maio 2012.

BARDIN, L. Análise de conteúdo. Lisboa: Edições 70, 1994.

BARRADALE, M. J. Impact of public policy uncertainty on renewable energy investment: wind power and the production tax credit. Energy Policy, v. 38, n. 12, p. 7698-7709. Special Section: Carbon Reduction at Community Scale, 2010.

BERMANN, C. Crise ambiental e as energias renováveis. Ciência e Cultura, v. 60, n. 3, p. 20-29, 2008.

BESSANT, J.;TIDD, J. Inovação e empreendedorismo. Porto Alegre: Bookman, 2009.

CNI. Confederação Nacional da Indústria. Energia eólica: panorama mundial e perspectivas no Brasil. Brasília, 2009.

FASSIN, Y. The stakeholder model refined. Journal of Business Ethics, v. 84, n. 1, p. 113$135,2009$.

FISCHLEIN, M.; LARSON, J.; HALL, D. M; CHAUDHRY, R; PETERSON, T. R; STEPHENS, J. C; WILSON, E. J. Policy stakeholders and deployment of wind power in the sub-national context: a comparison of four U.S. states. Energy Policy, v. 38. p. 4429-4439, 2010 . 
Fatores determinantes para o avanço da energia eólica no Estado do Ceará frente aos desafios das mudanças climáticas

FORSYTH, T. Promoting the "'Development Dividend" of Climate Technology Transfer:

Can Cross-sector Partnerships Help? World Development, v. 35, n. 10, p. 1684-1698, 2007.

GALLAGHER, K. S.; HOLDREN, J. P.; SAGAR, A. D. Energy-Technology Innovation. Annual Review of Environment and Resources, v. 31, p. 193-237, 2006.

GAN, J.; SMITH, C. T.; Drivers for renewable energy: a comparison among OECD countries. Biomass and Bioenergy, v. 35, n. 11, p. 4497-4503, 2011.

GARRONE, P; GRILLI, L. Is there a relationship between public expenditures in energy R\&D and carbon emissions per GDP? An empirical investigation. Energy Policy, v. 38, p. 5600-5613, 2010.

GWEC. GLOBAL WIND ENERGY COUNCIL. Global Wind Energy Outlook 2010. 2010. Disponível em: <http://www.gwec.net/fileadmin/documents/Publications/GWEO\% 202010\% 20final.pdf $>$. Acesso em: 20 fev. 2011.

HELM, D. The Assessment: Climate-Change Policy. Oxford Review of Economic Policy, v. 19, n. 3, p. 349-361, 2003.

. Government failure, rent-seeking, and capture: the design of climate change policy. Oxford Review of Economic Policy, v. 26, n. 2, p. 182-196, 2010.

HOFFMAN. The coming market shift: Climate change and business strategy. In: TANG, K.; YOEH, R. (eds.). Cut Carbon, Grow Profits: Business Strategies for Managing Climate Change and Sustainability. London: Middlesex University Press, p. 101-118, 2007.

; WOODY, J. G. Climate change: what's your business strategy? Boston, MA:

Harvard Business School Publishing Corporation, 2008.

JOHNSON, K. Brazil and the Politics of the Climate Change Negotiations. The Journal of Environment Development, v. 10, n. 2, p.178-206, 2001.

KOLK, A.; PINKSE, J. Market strategies for climate change. European Management Journal, v. 22, n. 3, p. 304-314, 2004.

Business responses to climate change: identifying emergent strategies. California Management Review, v. 47, n. 3, p. 6-20, 2005. 
Mônica Cavalcanti Sá de Abreu, Alexandra Alencar Siebra, Larissa Teixeira da Cunha $\&$ Sandra Maria dos Santos

Towards strategic stakeholder management? Integrating perspectives on sustainability challenges such as corporate responses to climate change. Corporate Governance, v. 7, n. 4, p. 370-378, 2007.

; HOFFMANN, V. Business, Climate Change and Emissions Trading: Taking Stock and Looking Ahead. European Management Journal, v. 25, n. 6, p. 411-414, 2007. LEWIS, J. I.; WISER, R. H. Fostering a renewable energy technology industry: an international comparison of wind industry policy support mechanisms. Energy Policy, v. 35, n. 3, p. 1844-1857, 2007.

MATHIESEN, B. V.; LUND, H.; KARLSSON, K. 100\% Renewable energy systems, climate mitigation and economic growth. Applied Energy, v. 88, n. 2, p. 488-501, 2011.

NEWELL, R. G. The role of markets and policies in delivering innovation for climate change mitigation. Oxford Review of Economic Policy, v. 26, n. 2, p. 253-269, 2010.

NOGUEIRA, L. P. P. Estado atual e perspectivas futuras para a energia eólica no Brasil. 2011. 137 f. Dissertação (Mestrado Planejamento Energético, COPPE) - Universidade Federal do Rio de janeiro, Rio de janeiro, 2011.

REN21. Renewable Energy Policy Network for the 21st Century. Renewables 2010: Global Status Report. REN 21 Secretariat, Paris, França, 2010.

SAGAR, A. D.; VAN DER ZWAAN, B. Technological innovation in the energy sector: R\&D, deployment, and learning-by-doing. Energy Policy, v. 34, p. 2601-2608, 2006.

SAIDUR, R.; ISLAM, M. R; RAHIM, N. A; SOLANGI, K. H. A review on global wind. Energy Policy. Renewable and sustainable energy reviews, v. 14, p. 1744-1762, 2010.

SCHULTZ, K.; WILLIAMSON, P. Gaining Competitive Advantage in a Carbon-constrained World: Strategies for European Business. European Management Journal, v. 23, n. 4, p. 383-391, 2005.

SHALIZI, Z.; LECOCQ, F. To mitigate or to adapt: is that the question? Observations on an appropriate response to the climate change challenge to development strategies. The World Bank Research Observer, v. 25, n. 2, p. 295-321, 2010.

TERCIOTE, R. A energia eólica e o meio ambiente. Campinas: UNICAMP, 2002. 
Fatores determinantes para o avanço da energia eólica no Estado do Ceará frente aos desafios das mudanças climáticas

THORNE, S. Towards a framework of clean energy technology receptivity. Energy Policy, v. 36, p. 2831-2838, 2008.

VALENTINE S. V. A step toward understanding wind power development policy barriers in advanced economies. Renewable and Sustainable. Energy Reviews, v. 14, p. 2796-2807, 2010.

VINE, E. Breaking down the silos: integration of energy efficiency renewable energy, demand response and climate change. Energy Efficiency, v. 1, p. 9-63, 2008.

VOLLENBROEK, F. A. Sustainable development and the challenge of innovation. Journal of Cleaner Production, v. 10, p. 215-223, 2002. 